\title{
Ecological correlates to cranial morphology in Leporids (Mammalia, Lagomorpha)
}

Brian P Kraatz, Emma Sherratt, Nicholas Bumacod, Mathew J Wedel

The mammalian order Lagomorpha has been the subject of many morphometric studies aimed at understanding the relationship between form and function as it relates to locomotion, primarily in postcranial morphology. The leporid cranial skeleton, however, may also reveal information about their ecology, particularly locomotion and vision. Here we investigate the relationship between cranial shape and the degree of facial tilt with locomotion (cursoriality, saltation, and burrowing) within crown leporids. Our results suggest that facial tilt is more pronounced in cursors and saltators compared to generalists, and that increasing facial tilt may be driven by a need for expanded visual fields. Our phylogenetically informed analyses indicate that burrowing behavior, facial tilt, and locomotor behavior do not predict cranial shape. However, we find that variables such as bullae size, size of the splenius capitus fossa, and overall rostral dimensions are important components for understanding the cranial variation in leporids. 
ECOLOGICAL CORRELATES TO CRANIAL MORPHOLOGY IN LEPORIDS (MAMMALIA,

6

\section{LAGOMORPHA)}

Brian P. Kraatz ${ }^{1}$, Emma Sherratt ${ }^{2}$, Nicholas Bumacod $^{3}$, Mathew J. Wedel ${ }^{1,4}$

${ }^{1}$ College of Osteopathic Medicine of the Pacific, Western University of Health Sciences, Pomona, CA USA 91766

${ }^{2}$ Department of Ecology, Evolution, and Organismal Biology, Iowa State University, Ames, IA 50011, USA

${ }^{3}$ College of Dental Medicine, Western University of Health Sciences, Pomona, CA USA 91766

${ }^{4}$ College of Podiatric Medicine, Western University of Health Sciences, Pomona, CA USA 91766

SHORT TITLE: Cranial morphology in leporids

KET WORDS: Cranial morphology, Leporidae, locomotion

Corresponding author: $\quad$ Brian P. Kraatz

College of Osteopathic Medicine of the Pacific

Western University of Health Sciences

309 East $2^{\text {nd }}$ Street

Pomona, CA 91711

Email: bkraatz@westernu.edu

Phone: (909) 706-3835 


\section{ABSTRACT}

25 The mammalian order Lagomorpha has been the subject of many morphometric studies aimed at understanding the relationship between form and function as it relates to locomotion, primarily in postcranial morphology. The leporid cranial skeleton, however, may also reveal information about their ecology, particularly locomotion and vision. Here we investigate the relationship between cranial shape and the degree of facial tilt with locomotion (cursoriality, saltation, and burrowing) within crown leporids. Our results suggest that facial tilt is more pronounced in cursors and saltators compared to generalists, and that increasing facial tilt may be driven by a need for expanded visual fields. Our phylogenetically informed analyses indicate that burrowing behavior, facial tilt, and locomotor behavior do not predict cranial shape. However, we find that variables such as bullae size, size of the splenius capitus fossa, and overall rostral dimensions are important components for understanding the cranial variation in leporids. (1)

(1)

\section{,} 39

\section{西} 1 2 43 4 5 6

\section{INTRODUCTION}


The relationship between form and function as it relates to locomotion has been extensively studied in a wide range of vertebrate groups (Webb, 1984; Hildebrand, 1988; Rayner, 1988; Aerts et al., 2000). The mammalian order Lagomorpha has been the subject of many morphometric studies aimed at understanding this relationship in postcranial morphology (e.g., Reese et al., 2013; FostowiczFrelik, 2007; Seckel and Janis, 2008, Young et al., 2014), and the impetus of these is largely to understand the high-speed form of leaping observed in some leporids (rabbits and hares). Leporids are peerless cursors for their size; some hares have been shown to achieve speeds greater than $70 \mathrm{~km} / \mathrm{h}$ (Garland, 1983). Indeed, the leporid postcranial skeleton exhibits many derived features that are strongly associated with saltation and cursoriality, including limb element elongation (Szalay, 1985; Fostowicz-Frelik, 2007; Seckel and Janis, 2008).

The cranial skeleton is more often overlooked in studies of form and locomotion, though there are biologically relevant associations between skull form and locomotor behavior, such as the role of the skull in active headfirst burrowing (e.g., Gans 1974; Barros et al. 2011; Sherratt et al. 2014; Hopkins and Davis, 2009; and see Wake 1993 for a review). In leporids, it has been suggested that morphological transformations of the skull may also be related to their ecology, particularly locomotion and vision (DuBrul, 1950; Bramble, 1989). The leporid skull is highly transformed, exhibiting a combination of features that clearly distinguish it from a more typical mammalian skull. A striking, yet often overlooked, characteristic is the broad dorsal arching of the cranium (Thompson, 1942), which is achieved via expansion and folding of the supraoccipital, and a distinct flexure near the basisphenoid/presphenoid suture (Fig. 1). A prominent ridge on the dorsal portion of the posterior cranial roof, which is superficially similar to an occipital crest, is actually a distinct flexure within the supraoccipital bone. Based on the position of the rabbit skull in resting position (De Beer, 1947: Fig. 9; Vidal et al. 1986: Fig. 4B, and see our Fig. 2), this flexure results in significant tilting of the facial region ventrally relative to the basicranium, which we here refer to as Facial Tilt (FT). DuBrul (1950) 
72 discusses this feature in detail within hares, and points out that the facial tilt of leporids is likely related 73 to their unique mode of locomotor behavior. DuBrul (1950) also discusses the similarities in leporid 74 skull transformations to those of our own lineage; in our hominin relatives, increased basicranial 75 flexion is associated with the onset of bipedal locomotion (Strait and Ross, 1999).

The goal of this study is to investigate the relationship between cranial shape and locomotion (cursoriality, saltation, and burrowing) within crown leporids. Our study is driven by hypotheses previously stated (DuBrul, 1950; Bramble, 1989) but never quantitatively tested. We use a large morphometric dataset spanning 16 phylogenetically constrained extant taxa (table 1) to evaluate hypotheses about the relationship between skull shape and facial tilt with locomotor ecology.

\section{STUDY SYSTEM AND HYPOTHESES}

The mammalian order Lagomorpha is composed of two families, Leporidae (rabbits and hares) and Ochotonidae (pikas). Ochotonids are represented by one living genus, Ochotona, which includes two North American and 28 Eurasian species (Alves and Hackländer, 2008). Leporids include 11 living genera with 62 species overall. The majority of species are found within two genera (Alves and Hackländer, 2008); Lepus (hares, 32 species) and Sylvilagus (a portion of rabbits, 17 species). Of the remaining nine genera, seven are monotypic, while two genera, Nesolagus and Pronolagus, only include two and four species, respectively. Overall, sixteen leporids species are currently considered endangered or critically endangered by the IUCN (Alves and Hackländer, 2008), and conservation issues are compounded by the lack of natural history data for many of these species. Leporids are found on every continent except Antarctica, from the high arctic to dry, hot deserts (Chapman and Flux, 1990, 2008). Some leporids are nocturnal, some are social, and some live in dense cover as opposed to the open plains often associated with these animals (Stoner et al., 2003). In terms of size, our study includes (Appendix 1) the smallest leporid, Brachylagus (mean skull length $\sim 50 \mathrm{~mm}$ ) to one 
96 of the largest, Lepus timidus (mean skull length $\sim 90 \mathrm{~mm}$ ). Genera such as Pentalagus and Caprolagus

97 have heavy, robust skulls, compared to the typically gracile skulls of most taxa. These cranial

98 differences manifest themselves morphometrically via a wide range of snout lengths and marked

99 differences in skull robustness and form (Fig. 1). While leaping abilities are common among most

100 leporid lineages, they are also known to be facultatively semiaquatic, scansorial, fossorial, or exhibit a

101 more generalized, non-hopping form of locomotion (Chapman and Flux, 2008). We distinguish here

102 between the saltatory locomotion (i.e., hopping) most typical among leporids (Table 1, Fig. 3), and its

103 cursorial form observed in some hare lineages (Gambaryan and Hardin, 1974; Bramble, 1989).

104 Generalists are recognized as those who don't exhibit clear hopping, but rather move in a more

105 scampering habit.

106

107

\section{Hypothesis 1 - Facial Tilt}

108 A high degree of facial tilting (e.g., ventral flexion of the facial region) should a) be positively

109

110

111

112

113

correlated with more active (e.g., saltatorial or cursorial) locomotor styles, and b) show no correlation with burrowing habit.

Variation in the degree of facial tilt among leporids has strong effects on orbital orientation (Fig. 3).

There is substantial literature discussing the relationship between orbit orientation and ecology within vertebrates (Noble, et al., 2000; Cox, 2008; Heesy, 2008; Iwaniuk et al., 2008; Jeffery and Cox, 2010), and Cartmill (1970) established the terms 'orbital convergence' and 'frontation' to understand these relationships. While orbit orientation is influenced by brain size and jaw mastication (Lieberman et al. 2000; Cox, 2008), within primates, orbital convergence is also strongly associated with increased binocular visual field overlap observed in nocturnal predatory species (Heesy, 2004, Heesy 2008). Various groups exhibit a high degree of both orbital convergence and orbital frontation (Cox and Jeffery, 2008), with hominids serving as an exemplar; orbital frontation is strongly positively 
correlated with basicranial flexion (Ross, 1995). As DuBrul (1950) points out, facial tilt

transformations among leporids are nearly identical to basicranial flexion observed within anthropoids; increased facial tilt and basicranial flexion both result in increased orbital frontation (see Fig. 2 for changes in frontation related to increased FT). Several workers have shown that increased frontation is positively correlated with arboreal taxa (Cartmill, 1970; Heesy, 2008); increased frontation changes the visual field to allow for better visualization of substrate. Jeffery and Cox (2010) show that leporids have relatively low degrees of convergence and frontation. As we discuss below, however, when facial tilt is taken into consideration, leporids actually demonstrate a relatively higher degree of frontation (as indicated by the orbital plane relative to the vertical plane). More importantly, regardless of the absolute measure of frontation within leporids, we expect that frontation will vary among leporids correlated with varying degrees of facial tilt. For this reason, we expect that facial tilt (as a proxy for frontation) should be strongly correlated to locomotor styles that would require enhanced substrate perception (saltatorial and cursorial), but we do not expect that facial tilt will be related to burrowing habit.

\section{Hypothesis 2 - Skull shape}

We expect that there will be significant skull shape differences among a) locomotor styles, and b) burrowing habits.

We have no a priori expectations about how overall skull shape might change with locomotor mode or burrowing habit. Instead we will investigate the more fundamental question of whether skull shape is related to locomotion and burrowing habit at all. Our interest in this question is therefore more a form of exploratory data analysis than a test of a specific hypothesis. 
We collected morphometric data (Table 2; Appendix 1) from 140 leporid skulls spanning 16 taxa (Table 1) housed in the departments of Mammalogy at the American Museum of Natural History $(\mathrm{AMNH})$ and the Los Angeles County Museum of Natural History (LACM). Care was made to use only adult specimens, characterized by fully fused occipital sutures (Hoffmeister and Zimmerman, 1967). Ten linear measurements (Table 3, Figure 3) were recorded per specimen using digital calipers by three authors (BPK, MW, and NB), and a repeatability analysis (consisting of 10 specimens measured 3 times, results not presented) was performed to ensure there was no intercollector bias introduced. The ten cranial measurements were analyzed using the log-shape ratios approach (Mosimann, 1970; Mosimann and James, 1979). For each specimen, size was computed as the geometric mean of all measurements, and then each measurement was divided by size to obtain the shape ratios. We then used the log of this quantity as raw data for the subsequent analyses.

Facial tilt was measured by photographing each skull in lateral view using a Nikon D80 digital camera. The skulls were placed in a sandbox to ensure that the sagittal plane was orthogonal to the focal direction. Facial tilt angle was acquired from the digital photos within Adobe Photoshop C, measured as the angular difference between the 'occipital plane' and a line parallel to the cranial diastema (Fig. 3). Variation among individuals for the cranial variables weas explored using principal components analysis on the covariance matrix of the log-shape ratios shape variables within the statistical software R v3.1.1 (R Core Team 2014, http://cran.r-project.org/).

\section{Phylogenetically informed analyses}

To examine facial tilt angle and cranial shape in a phylogenetic context, we used the phylogenetic relationships among species of Leporidae recently published by Matthee et al. (2004). The original tree was constructed using seven genes (five nuclear and $2 \mathrm{mt}$ ) for 25 ingroup taxa. We pruned the tree using Mesquite (C) (Maddison and Maddison, 2015) to include only the 16 taxa studied 
here (Fig. 3), and retained the information on branch lengths (details of which are in Matthee et al. 2004).

We first examined the amount of phylogenetic signal in the morphometric variables, calculating the $K$ statistic (Blomberg et al. 2003) for facial tilt angle, and the multivariate equivalent $K_{\text {mult }}$ (Adams 2014a) for all log-shape ratios. The $K$ statistics provide a measure of the strength of phylogenetic signal for univariate and multivariate traits respectively, and in each case provides a single statistic. A value of less than one implies that taxa resemble each other phenotypically less than expected under Brownian motion, while values of more than 1 implies that close relatives are more similar to one another phenotypically than expected under Brownian motion. Significance testing was performed using a permutation procedure whereby the variables are randomized relative to the tree, and 1000 permutations were performed for each test (Blomberg et al. 2003).

Log-shape ratios and facial tilt angle were compared to several key ecological indicators, including locomotor type and burrowing habit (Table 1). Ecological data were obtained from Chapman and Flux (1990) and Stoner et al. (2003). We divided leporids into three locomotor categories: generalized or 'scramble' locomotors, which tend to be the slowest-moving; saltatory or hopping locomotors; and fast-moving taxa that practice cursorial (leaping and bounding) locomotion, which is essentially a specialized form of saltation. Regarding burrowing habits, some leporids dig their own burrows (e.g., Oryctolagus and Romerolagus), whereas others simply occupy preexisting burrows excavated by other animals. For the purposes of this study, we refer to leporids as burrowers if they occupy burrows consistently, regardless of whether they dig the burrows.

To test whether or not the degree of facial tilt differs among the three locomotor categories, we performed a one-way Analysis of Variance (ANOVA) in an evolutionary context, under a Brownian motion model of evolution. This was done by using species means of the FT angle in a distance-based phylogenetic generalized least squares analysis (D-PGLS ; Adams 2014b). A distance-based approach 
192 provides numerically identical estimates of evolutionary patterns to those obtained from standard 193 implementations of PGLS on univariate datasets, and was used here for consistency with analyses 194 below on the log-shape ratios. The statistical significance of each term in the D-PGLS was assessed using 1000 permutations whereby the species means are shuffled among the tips of the phylogeny. We performed a second ANOVA as above to test whether facial tilt differs between taxa that utilize burrows ("burrowing") and those that do not ("non-burrowing"). Box and whisker plots were used to visualize the individual variation in facial tilt angle among groups.

To test whether or not cranial shape, as represented by ten morphometric variables, differs among the three locomotor types, we performed a multivariate analysis of variance in an evolutionary context under a Brownian motion model of evolution. This was done a D-PGLS with the species means of the ten log-shape ratios. The D-PGLS performs better than a regular PGLS when the number of variables begins to approach the number of species (Adams 2014b). The statistical significance of each term in the D-PGLS was assessed using 1000 permutations of the species means. Similarly, we tested whether or not cranial shape differs between burrowing and non-burrowing taxa using a D-PGLS as above.

Finally, to test whether or not facial tilt is a significant predictor of cranial shape, we performed a multivariate regression in an evolutionary context, under a Brownian motion model of evolution, again using the D-PGLS approach. The statistical significance was assessed using 1000 permutations of the species means of the log-shape ratios. All of the phylogenetically informed analyses were done using the geomorph package (Adams et al. 2014) in the statistical software R v3.1.1 (R Core Team, 2014). The ANOVAs on FT, the MANOVAs on cranial log-shape rations, and the multivariate regression were done using the procD.pgls function, and phylogenetic signal was calculated with the physignal function. 


\section{RESULTS}

\section{Facial Tilt}

Facial tilt (FT) summarizes the broad dorsal arching of the skull roof that is prominent among living leporids (Fig. 3). Across the species in this study, the measure of facial tilt angle has a very low value for $K$, implying that the taxa resemble each other morphologically less than expected under Brownian motion, and the test is not significant $(K=0.62, P=0.53)$. Overall, there is a nearly $30^{\circ}$ range of variation in FT among specimens of all species in this sample (Appendix 1). We found a significant difference among locomotor types for facial tilt angle (D-PGLS, $F=7.02, P=0.016$; Fig. 5a). The mean FT angle for generalized locomotors (mean, $\mu=44.0$, standard deviation, $\sigma=5.48$ ) is substantially higher than that of cursorial $(\mu=36.3, \sigma=5.46)$ and saltatorial taxa $(\mu=37.2, \sigma=5.91)$ (Fig. 5a). This indicates that taxa that are either saltatorial or cursorial tend to have facial regions that are more ventrally deflected. By contrast, we found no significant difference in FT angle between burrowing and non-burrowing taxa (Fig. 5b; D-PGLS, $F_{=0} 0.0037, P=0.973$; Fig. 5b).

\section{Cranial shape analyses}

In a principal components analysis of the ten log-shape ratios among individuals, the first four PC axes account for $90.2 \%$ of total variance. PC1 accounts for $43.5 \%$ of cranial shape differences, PC2 accounts for $24.4 \%$, PC3 accounts for $13.2 \%$, and PC4 accounts for $9.0 \%$ of variance. (Table 3; Fig. 6).

The remaining PCs each contribute less than $10 \%$ of the total variation. A PCA of the species means (not shown) produced equivalent results $(\mathrm{PC} 1=42.6 \%, \mathrm{PC} 2=33.4 \%, \mathrm{PC} 3=11.3 \%, \mathrm{PC} 4=5.9 \%)$, and with the same variables contributing highly on each axis, and thus we present only one analysis for brevity.

The loadings of the PCA (Table 3) show that bullae diameter (BD; 0.85) has the strongest influence on PC1, substantially more than other variables. PC1 strongly separates Brachylagus, 
Romerolagus, and Bunolagus (all with larger bullae diameters) from all other leporid species (Fig. 6A). In terms of locomotor styles, cursorial species are isolated towards the negative portion of the PC1 axis. Similarly, PC2 strongly shows the effects of size of the splenius capitus fossa (SCF; -0.91). While this measure does not separate among saltators (Fig. 6B), there is some separation between generalists and cursorial species. Loadings for PC3 indicate that three variables are strongly affecting the variance along that axis: interorbital width (IOW; 0.68), nasal length (NL; -0.51), and diastema length (DILU; 0.42). PC3 shows separation of species (Fig. 6C), but no clear broader groupings. It also does not clearly distinguish locomotor modes, but saltators do occupy the negative portion of the axes where no generalists or cursors are found (Fig. 6D). Parietal length (PAL; -0.87) loads strongly along PC4. This axes does help to distinguish species (Fig. 6C), but shows little ability to distinguish among locomotor modes (Fig. 6D).

There is significant phylogenetic signal is cranial shape described by the ten log-shape ratios $\left(K_{\text {mult }}=0.91, P=0.035\right)$. The value of kappa is substantially higher than that for facial tilt, but still below 1, implying that close relatives are moderately less similar to one another phenotypically than expected under Brownian motion. Phylogenetically informed analysis of variance (D-PGLS) indicates that there is no significant effect of locomotor habit on cranial shape $(F=1.3712, P=0.28)$. Likewise, there is no significant effect on cranial shape by burrowing behavior $(F=1.2831, P=0.56)$. Finally, a phylogenetically informed multivariate regression suggests that facial tilt angle is not a significant predictor of cranial shape $\left(R^{2}=0.097, P=0.413\right)$

\section{DISCUSSION}

Given a clear correlation between the degree of facial tilt (FT) and locomotor style, and the lack of significant phylogenetic signal in FT angle, it is evident that this aspect of cranial morphology is strongly influenced by ecological factors within Leporidae. While the relationship between shape and 
264 function is established, the specific aspects of cranial shape that inform ecological function are only

265 partially resolved from our multivariate analyses. Generalized locomotors exhibit less facial tilt, an anatomical condition that could properly be thought to be primitive for the mammalian skull, and given their fossil record, lagomorphs as well (Dice, 1933; Asher et al., 2005). Facial tilt within leporids is allowed via the expansion of the supraoccipital bone on the dorsal skull (Fig. 2), and along the ventral skull, there is a pronounced flexure near the basisphenoid/presphenoid juncture.

The complex architecture of the supraoccipital in leporids is the most marked change related to the dorsal arching the skull roof, but there are additional effects on the orientation of the orbit (Fig. 2). There is a vast literature on orbital orientation as it relates to locomotion, visual acuity, brain size, and masticatory anatomy (Noble et al., 2000; Heesy, 2005; Heesy et al., 2007; Iwaniuk et al., 2008; Heesy, 2008; Cox, 2008; Jeffery and Cox, 2010), and perhaps most clearly, changes in orbit orientation have direct affects on the range of visual fields. Both orbital convergence and frontation are commonly measured orbital variables that seem to be functionally predictive (Cox, 2008); increased convergence is thought to increase binocular field overlap within primates (Ross and Martin 2007; Heesy et al., 2007), and orbital frontation allows for better substrate visualization (Cartmill, 1970; Heesy, 2008). While Jeffery and Cox (2010) demonstrated that the rabbit shows low degrees convergence and frontation, frontation in the rabbit is complicated by skull transformations associated with facial tilt. Traditionally, frontation was considered as the degree to which the orbital plane is aligned vertically (Cartmill, 1970; Ross, 1994); whereas, Jeffery and Cox (2010) used angular differences between the lateral semicircular canal and the medial and lateral orbital rectus muscles as a proxy for frontation. While these later measures are distinct for rabbits (Cox and Jeffery, 2008; Jeffery and Cox, 2010) as compared to other mammals, due to the way rabbits hold there heads (De Beer, 1947; Vidal et al. 1986), angular differences between the lateral semi-circular canal and horizontal rectus muscles may not be a perfect summary of the degree to which the orbital plane approaches vertical. Interestingly, as 
288 Jeffery and Cox (2010) show, humans and rabbits are outliers with regard to this metric, as they both demonstrate strong misalignment of semicircular canal and rectus muscle orientations. This may be driven by the fact that both of these species exhibit skull shapes in which the basicranium is highly transformed relative to the facial region (DuBrul, 1950). Most importantly, and regardless of the absolute degree of frontation, facial tilting within leporids would have the effect of changing the orientation of the orbit and increasing frontation. Our data show that variation in facial tilt among leporids $\left(\sim 30^{\circ}\right)$ is explained by mode of locomotion. Presumably, pronounced facial tilt and the associated increase in frontation improve substrate visibility in fast-moving taxa.

In contrast to FT angle, overall cranial morphology as described by ten log-shape ratio measurements is not significantly different among locomotor modes or between burrowers and nonburrowers. Instead, the PCA of individual variation in our cranial variables clearly shows that amongspecies variation is a strong driver of morphospace organization (Fig. 6). The phylogenetic structure evident in the cranial variables shown in our PCA is supported by a high measure of phylogenetic signal. However, there is some separation of the three locomotor modes in morphospace in (Fig. 6). Saltatorial species have a wide-variety of cranial morphologies, while the generalized locomotors are clustered in morphospace (in the negative quadrant of PC1 and PC2), likely due to their close ancestry. Bulla length contributes the most to the first PCA axis, separating out a group of three species (larger bullae; Romerolagus, Bunolagus, and Brachylagus) from all other leporids, and thus this morphological trait is a candidate feature of adaptive differences between the different locomotors styles. The external bulla is a complicated structure, which receives contributions from different bones across Mammalia (Novaek, 1977). The external auditory bulla has been shown to be of significant systematic importance within carnivorans (Hunt, 1974; Ivanoff, 2001), but the function of bulla size is unclear for leporids. Pavlinov and Rogovin (2000) showed that bulla size is negatively correlated with pinna size in specialized desert rodents. They specifically remark that faster, more agile rodents within 
312 these groups tend toward smaller bulla and larger pinnae. While our data do not explicitly test this, our 313 cursorial species appear toward the negative PC1 axes, which are represented by smaller bullae. We 314 also note that while Romerolagus and Brachylagus exhibit large bullae and relatively small pinnae,

315 Bunolagus does not fit this pattern as it has both large bullae and large pinnae. Liao et al. (2007) shows

that bulla size is negatively correlated with altitude in the Daurian pika, Ochotona dauurica

(Lagomorpha, Ochotonidae). This patterns does not match our observations, as one of our large bullae species, Romerolagus, is found at high elevations (Cervantes et al., 1990). We think that our PC1 axis may also reflect the relative size of the basicranium to the facial region within leporids, in addition to bullae size; we discuss this topic further below.

The second variable of interest, which loads strongly on PC2, is the splenius capitus fossae. Lateral to the external occipital protuberance (EOP; i.e. Inion) are two large fossae that extend to the parietal/occipital suture and allow for attachment of the splenius capitus mm. (Barone et al., 1973), which are involved in head extension and lateral rotation. The fossae can be clearly identified via the prominent superior nuchal line that extends rostrally from the EOP. The longissimus capitus $\mathrm{m}$. inserts with the splenius capitus $\mathrm{m}$. in the lateral, mastoid area, of the occipital region. A final long extensor muscle, the semispinalus capitus m., attaches to the lateral portions of the EOP. Together, these three long erectors serve to extend, stabilize, and laterally rotate the head (Igarashi et al., 2000). Upon comparison of leporid skulls (Fig. 1), it is apparent that those with significant facial tilt are expanding the rostral portions of the supraoccipital bone relative to the caudal portion, and indeed, this seems to be reflected in PC2 as the variance along that axis helps to separate out cursors (larger splenius capitus fossa) and generalists (smaller splenius capitus fossa). The expansion of the splenius capitus fossa should serve to increase the attachment area for the long extensor muscles, allowing for improved extension and lateral rotation of the head. 
It is worth noting that all variables strongly affecting PC1, PC2, and PC4 are associated with

336

337

338

339

340

341

342

343

344

345

346

347

the neurocranium, and variables affecting PC3 are all associated with the splanchnocranium. It has been thoroughly demonstrated within our own lineage, and mammals more broadly, that these basicranial and facial regions demonstrate strong levels of phenotypic independence (see, for example, Porto, et al., 2009; Drake and Klingenberg, 2010; Sanger, et al., 2012; Klingenberg, 2013) While this pattern is debated within humans and other great apes (Singh et al. 2011; Mitteroecker et al. 2012; Martinez-Abadias et al. 2012 ), some similarities in skull transformation between humans and rabbits have been noted in the literature (DuBrul, 1950; Moore and Spence, 1969). Moore and Spence (1969) highlighted that both humans and rabbits transform the facial regions relative to the basicranium, but also pointed out that the transformation seems to be driven in the facial regions within rabbits, whereas it seems to be driven from the basicranium in humans. While our data do not directly address modularity or developmental pathways within leporid skulls, it would be useful to understand how relative transformation between the facial and basicranial regions within leporids, which seems to influence facial tilt, could be explained mechanistically by these developmental trajectories.

Most importantly, it is striking that facial tilt does distinguish generalist locomotors clearly from more active taxa within leporids. This suggests that FT represents a meaningful biological metric among leporids, but may also summarize a specific aspect of cranial shape not recognized, but alluded to, within our linear variables. While our linear measurements failed to strongly discern differences among locomotor groups, this may be a function of the limited ability of these variables to capture important shape differences among crania within leporids due to the highly transformed nature of their skulls (e.g. pronounced dorsal arching). Nonetheless, our linear variables do separate taxonomic groups, as has been done in other studies (see, for example, Palacios et al., 2008 and Pintur et al. 2014). Our study demonstrates that the dorsal arching found within leporid skulls, mainly represented here as facial tilt, has a strong relationship with how these animals moved. Facial tilt is related to a 
complex transformation of nearly all aspects of the leporid skull, including basicranial rearrangement and facial changes in the diastema region. Our linear variables, in addition to distinguishing taxonomic groups, also capture some aspects of these changes related to locomotion. Based on the changes in orbit orientation that are associated with increased facial tilt, it is likely that skull transformations in crown leporids are driven by a need for increased visual perception of substrate.

\section{AUTHOR CONTRIBUTIONS}

Conceived and designed the experiments: BPK, MJW. Performed the experiments: BPK, NB, ES. Analyzed the data: BPK, NB, ES. Contributed reagents/materials/analysis tools: BPK, NB, ES, MJW. Wrote the paper: BPK, NB, MJW, ES.

\section{ACKNOWLEDGEMENTS}

We are grateful to Neil Duncan and Eileen Westwig of the American Museum of Natural History and Jim Dines of the Natural History Museum of Los Angeles County for access to specimens in their care. 
392 LITERATURE CITED

393 Adams DC. 2014a. A generalized K statistic for estimating phylogenetic signal from shape and other 394 high-dimensional multivariate data. Systematic Biology 63(5):685-697.

396 Adams DC. 2014b. A method for assessing phylogenetic least squares models for shape and other 397 high-dimensional multivariate data. Evolution 68:2675-2688.

398

399 Adams DC, Collyer ML, Otarola-Castillo E, Sherratt E. 2014. Geomorph: Software for geometric 400 morphometric analyses. R package version 2.1: cran.r-project.org/web/packages/geomorph/index.html. 
405 Alves PC, Hackländer K. 2008. Lagomorph species: geographical distribution and conservation status.

406 In: Alves PC, Ferrand N, and Hackländer K, eds. Lagomorph biology: evolution, ecology, and 407 conservation. Heidelberg: Springer, 395-405.

408

409 Asher RJ, Meng J, Wible JR, McKenna MC, Rougier GW, Dashzeveg D, Novacek MJ. 2005. Stem

410 Lagomorpha and the antiquity of Glires. Science 307(5712):1091-1094.

411

412

Barone R, Pavaux PC, Blin B. 1973. Atlas d'anatomie du lapin [Atlas of rabbit anatomy]. Paris:

413 Masson.

414

415

416

417

24(11):2423-2433.

418

419

Blomberg S, Garland T Jr, Ives AR. 2003. Testing for phylogenetic signal in comparative data:

420

behavioral traits are more labile. Evolution, 57(4), pp.717-745.

421

422

423

Bramble DM. 1989. Axial-appendicular dynamics and the integration of breathing and gait in mammals. American Zoologist 29(1):171-186.

Cartmill M. 1970. The orbits of arboreal mammals. PhD dissertation, University of Chicago, Chicago, 426 Illinois, USA.

428 Cervantes FA, Lorenzo C, Hoffmann RS. 1990. Romerolagus diazi. Mammalian Species, 1-7. 
430 Chapman JA, Flux JE (Eds). 1990. Rabbits, hares and pikas: status survey and conservation action 431 plan. Gland, Switzerland: International Union for Conservation of Nature and Natural Resources.

432

433 Chapman JA, Flux JE. 2008. Introduction to the Lagomorpha. In: Alves PC, Ferrand N, and

434 Hackländer K eds, Lagomorph biology: evolution, ecology, and conservation. Heidelberg: Springer, 14359.

436

437 Cox, PG. 2008. A quantitative analysis of the Eutherian orbit: correlations with masticatory apparatus. 438 Biological Reviews 83(1):35-69.

439

440 De Beer GR. 1947. How animals hold their heads. Proceedings of the Linnean Society of London $441 \quad 159(2): 125-139$.

Dice LR. 1933. Some characters of the skull and skeleton of the fossil hare, Palaeolagus haydeni.

444 Papers of the Michigan Academy of Sciences and Arts and Letters 18:301-306.

446 Drake AG, Klingenberg CP. 2010. Large-scale diversification of skull shape in domestic dogs:

447 disparity and modularity. The American Naturalist 175(3): 289-301.

449 DuBrul EL. 1950. Posture, locomotion and the skull in Lagomorpha. American Journal of Anatatomy $450 \quad 87(2): 277-313$. 
453 Fostowicz-Frelik Ł. 2007. Revision of Hypolagus (Mammalia: Lagomorpha) from the Plio-Pleistocene 454 of Poland: qualitative and quantitative study. Annals of Zoology 57(3):541-590.

455

456 Gambaryan PP, Hardin H. 1974. How mammals run: anatomical adaptations. New York: Wiley. 357 p.

457

458 Gans C. 1974. Biomechanics: an approach to vertebrate biology. Ann Arbor, Michigan, United States:

459 The University of Michigan Press. 272 p.

460

461 Garland T Jr. 1983. The relation between maximal running speed and body mass in terrestrial 462 mammals. Journal of Zoology 199:157-170.

463

464

Hildebrand M. 1988 Analysis of Vertebrate Structure. 3rd ed. NewYork: John Wiley and Sons. mammals. Anatomical Record 281A:1104-1110.

Heesy. CP. 2005. Function of the mammalian postorbital bar. Journal of morphology 264(3): 363-380.

Heesy CP. 2008. Ecomorphology of orbit orientation and the adaptive significance of binocular vision 472 in primates and other mammals. Brain, Behavior and Evolution 71(1):54. 
474 Heesy CP, Ross CF, Demes B. 2007. Oculomotor stability and the functions of the postorbital bar and 475 septum. In: Ravosa MJ, Dagosto, M, eds. Primate Origins: Adaptations and Evolution. New York: 476 Springer, 257-283.

477

478 Hoffmeister DF, Zimmerman EG. 1967. Growth of the skull in the cottontail (Sylvilagus floridanus) 479 and its application to age determination. American Midland Naturalist 78:198-206.

480

481 Hopkins SB, Davis EB. 2009. Quantitative morphological proxies for fossoriality in small mammals. 482 Journal of Mammalogy 90:1449-1460.

483

484 Hunt RM. 1974. The auditory bulla in Carnivora: an anatomical basis for reappraisal of carnivore 485 evolution. Journal of Morphology 143(1):21-75.

486

Igarashi N, Yamamura K, Yamada Y, Kohno S. 2000. Head movements and neck muscle activities associated with the jaw movement during mastication in the rabbit authors. Brain Research 871(1):151-

489 155.

490

491 Ivanoff DV. 2001. Partitions in the carnivoran auditory bulla: Their formation and significance for 492 systematics. Mammal Review 31(1):1-16.

493

494 Iwaniuk AN, Heesy CP, Hall MI, Wylie DR. 2008. Relative Wulst volume is correlated with orbit 495 orientation and binocular visual field in birds. Journal of Comparative Physiology A 194(3):267-282. 
497 Jeffery N, Cox PG. 2010. Do agility and skull architecture influence the geometry of the mammalian 498 vestibulo-ocular reflex? Journal of Anatomy 216(4):496-509.

499

500 Klingenberg CP. 2013. Cranial integration and modularity: insights into evolution and development 501 from morphometric data. Hystrix, the Italian Journal of Mammalogy 24(1):43-58.

502

503 Liao J, Zhang Z, Liu N. 2007. Effects of altitudinal change on the auditory bulla in Ochotona daurica 504 (Mammalia, Lagomorpha). Journal of Zoological Systematics and Evolutionary Research 45(2):151505154.

506

507 Lieberman DE, Ross CF, Ravosa, MJ. 2000. The primate cranial base: ontogeny, function, and 508 integration. American Journal of Physical Anthropology 113(s 31):117-169.

509

510 Maddison WP, Maddison DR. 2015. Mesquite: a modular system for evolutionary analysis. Version $5113.02 \mathrm{http}: / /$ mesquiteproject.org

512

513 Martínez-Abadías N, Esparza M, Sjøvold T, González-José R, Santos M, Hernández M, Klingenberg

514 CP. 2012. Pervasive genetic integration directs the evolution of human skull shape. Evolution 515 66(4):1010-1023.

516

517 
518 Matthee, CA, Van Vuuren, BJ, Bell, D, Robinson, TJ. 2004. A molecular supermatrix of the rabbits 519 and hares (Leporidae) allows for the identification of five intercontinental exchanges during the 520 Miocene. Systematic Biology 53(3): 433-447.

521

522 Mitteroecker P, Gunz P, Neubauer S, Müller G. 2012. How to explore morphological integration in 523 human evolution and development? Evolutionary Biology 39(4):536-553.

524

525 Moore WJ, Spence TF. 1969. Age changes in the cranial base of the rabbit (Oryctolagus cuniculus).

526 The Anatomical Record 165(3):355-361.

527

528 Mosimann JE. 1970. Size allometry: size and shape variables with characterizations of the lognormal 529 and generalized gamma distributions. Journal of the American Statistical Association 65(330):930-945.

530

531 Mosimann JE, James FC. 1979. New statistical methods for allometry with application to Florida 532 redwinged blackbirds. Evolution 33:444-459

533

534 Noble VE, Kowalski EM, Ravosa MJ. 2000. Orbit orientation and the function of the mammalian 535 postorbital bar. Journal of Zoology 250(3):405-418.

536

537 Novacek MJ. 1977. Aspects of the problem of variation, origin and evolution of the eutherian auditory 538 bulla. Mammal Review 7:131-150. 
540 Palacios F, Angelone C, Alonso G, Reig S. 2008. Morphological evidence of species differentiation

541 within Lepus capensis Linnaeus, 1758 (Leporidae, Lagomorpha) in Cape Province, South Africa.

542 Mammalian Biology-Zeitschrift für Säugetierkunde 73(5):358-370.

543

544 Pavlinov II, Rogovin KA. 2000. Relation between size of pinna and auditory bulla in specialized desert

545 rodents. Zhurnal Obshchei Biologii 61:87-101 (in Russian).

546

547 Pintur K, Dančević N, Štedul I, Popović N, Slijepčević V. 2014. Craniometric features of European

548 hare (Lepus europaeus Pall.) from North-west Croatia and the island of Vir. Veterinarski arhiv

$549 \quad 84(4): 387-400$.

550

551 Porto A, de Oliveira FB., Shirai LT, De Conto V, Marroig G. 2009. The evolution of modularity in the

552 mammalian skull I: morphological integration patterns and magnitudes. Evolutionary Biology

$553 \quad 36(1): 118-135$.

554

Rayner JM. 1988. Form and function in avian flight. In: Johnston RF, ed, Current

Ornithology. New York: Springer, 1-66.

555

R Core Team. 2014._R: A language and environment for statistical computing. R Foundation for Statistical Computing, Vienna, Austria. URL http://www.R-project.org/.

Reese AT, Lanier HC, Sargis EJ. 2013. Skeletal indicators of ecological specialization in pika (Mammalia, Ochotonidae). Journal of Morphology 274(5):585-602. 
561 Ross CF. 1995. Allometric and functional influences on primate orbit orientation and the origins of the 562 Anthropoidea. Journal of Human Evolution 29(3):201-227.

564 Ross CF, Martin RD. 2007. The role of vision in the origin and evolution of primates. Evolution of

565 Nervous Systems 4:59-78.

Sanger TJ, Mahler DL, Abzhanov A, Losos JB. 2012. Roles for modularity and constraint in the evolution of cranial diversity among Anolis lizards. Evolution 66(5):1525-1542. osteological correlate for locomotory specialization. Journal of Mammalian Evolution 15:261-279.

Sherratt E, Gower DJ, Klingenberg CP, Wilkinson M. 2014. Evolution of cranial shape in caecilians (Amphibia: Gymnophiona). Evolutionary Biology 41(4): 4), 528-545. quantitative study of cranial integration in Homo, Pan, Gorilla and Pongo. Journal of Human Evolution 62(1):155-164. lagomorphs. Biological Journal of the Linnean Society 79(2):309-328.

582 Strait DS, Ross CF. 1999. Kinematic data on primate head and neck posture: implications for the 583 evolution of basicranial flexion and an evaluation of registration planes used in paleoanthropology. 584 American Journal of Physical Anthropology 108(2):205-222. 
586 Szalay FS. 1985. Rodent and lagomorph morphotype adaptations, origins, and relationships: some 587 postcranial attributes analyzed. In: Luckett WP, Hartenberger J-L. Evolutionary Relationships Among 588 Rodents. New York: Springer, 83-132.

589

590 Thompson, D. W. 1942. On growth and form. $2^{\text {nd }}$ Ed. New York: Macmillan.

591

592 Vidal PP, Graf W, Berthoz A. 1986. The orientation of the cervical vertebral column in unrestrained 593 awake animals. Experimental Brain Research 61:549-559.

594

595 Wake MH. 1993. The skull as a locomotor organ. In: Hanken J, Hall BK, editors. The Skull, volume 3:

596 Functional and Evolutionary Mechanisms. Chicago: University of Chicago Press, 197-240.

597

598 Webb PW. 1984. Body form, locomotion and foraging in aquatic vertebrates. American Zoologist 599 24(1):107-120.

600

601 Young JW, Danczak R, Russo GA, Fellmann, CD. 2014. Limb bone morphology, bone strength, and 602 cursoriality in lagomorphs. Journal of Anatomy 225:403-418.

603

604 


\section{1}

Disparity of leporid skulls

FIGURE 1 - Disparity in facial tilt and cranial shape in selected leporids, including a) Brachylagus idahoensis (LACM 447; SLD 50mm), b) Lepus capensis (LACM 40152; SLD $82 \mathrm{~mm}$ ), c) Poelagus marjorita (AMNH 51056; SLD 80mm), d) Pronolagus crassicaudatus (AMNH 89033; SLD 80mm), e) Lepus americanus (LACM 93737; SLD 75mm), f) Oryctolagus cuniculus (AMNH 166951; SLD 78mm), g) Nesolagus timminsi (AMNH 272419; SLD 78mm), h) Bunolagus monticularis (AMNH 146662; SLD 78mm), and i) Romerolagus diazi (AMNH 148181; SLD 60mm). All skull images are scaled to approximately the same skull length, skull length measurements are an approximation based on our measured specimens.
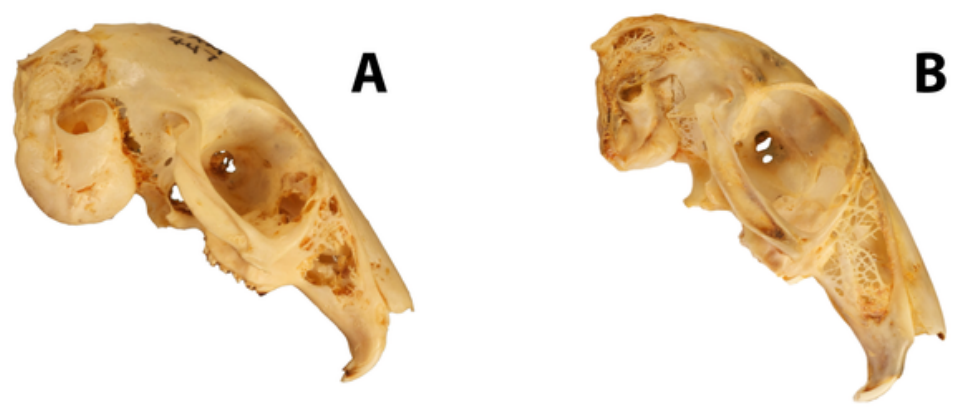

B
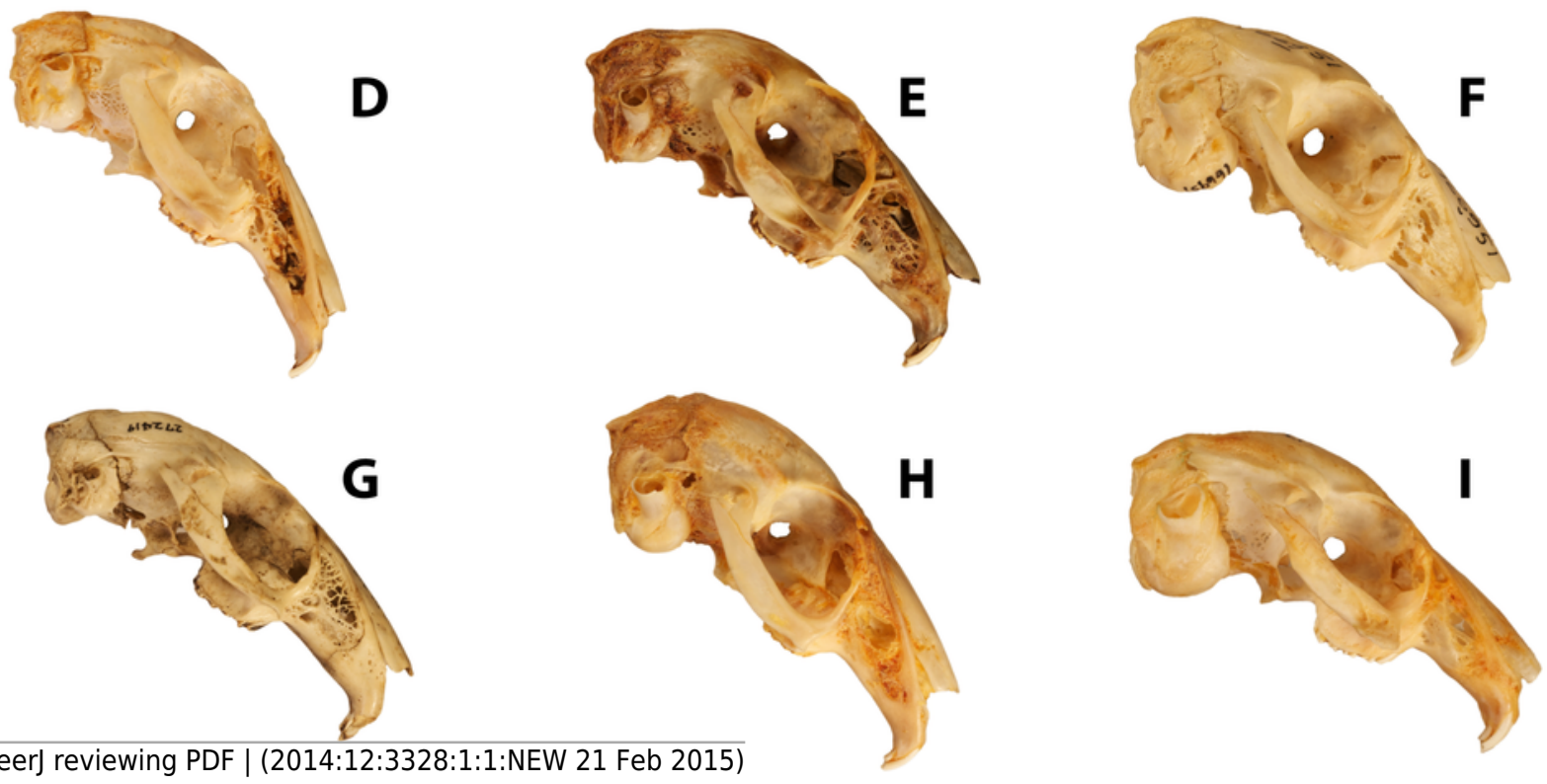
2

Facial tilt in leporids

FIGURE 2 - Facial tilt in leporids. The crania of a) Caprolagus hispidus (AMNH 54852, above) and b) Pronolagus crassicaudatus (AMNH 89033, below) are shown in left lateral view. Facial tilt (FT) is defined herein as the angle between the upper diastema and the occipital plane, where increased values indicated a skull orientation closer the horizontal plane. The triangle indicated the position of the external occipital protuberance (EOP), and from that, both the dorsal (red) and occipital (blue) extend of the supraoccipital bones is outlined. 


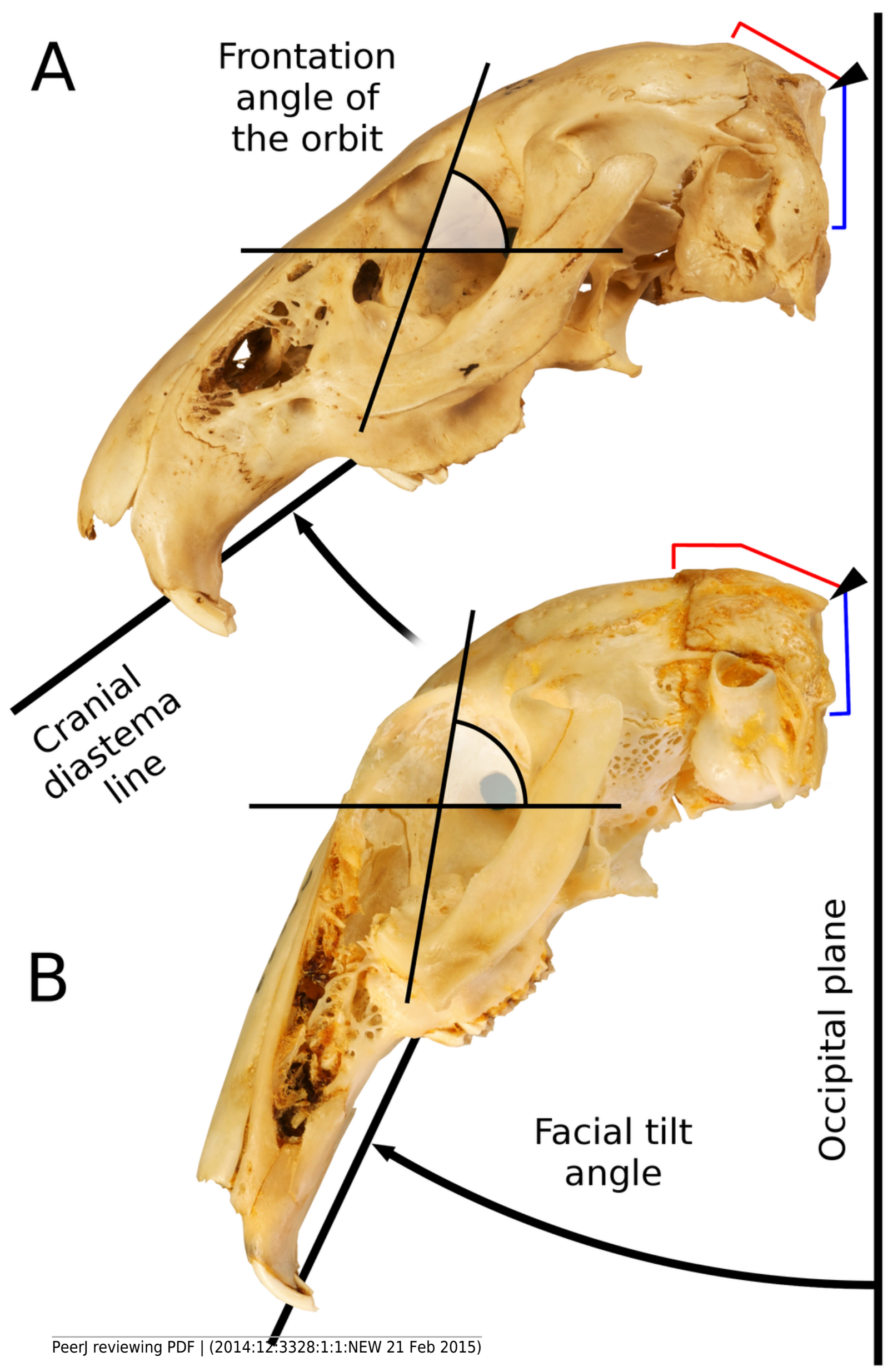




\section{3}

Phylogeny of Leporidae

FIGURE 3 - The phylogenetic hypothesis of the 16 taxa used in this study, pruned from the supermatrix maximum likelihood phylogeny in Matthee et al (2004). Locomotor styles from Table 1.

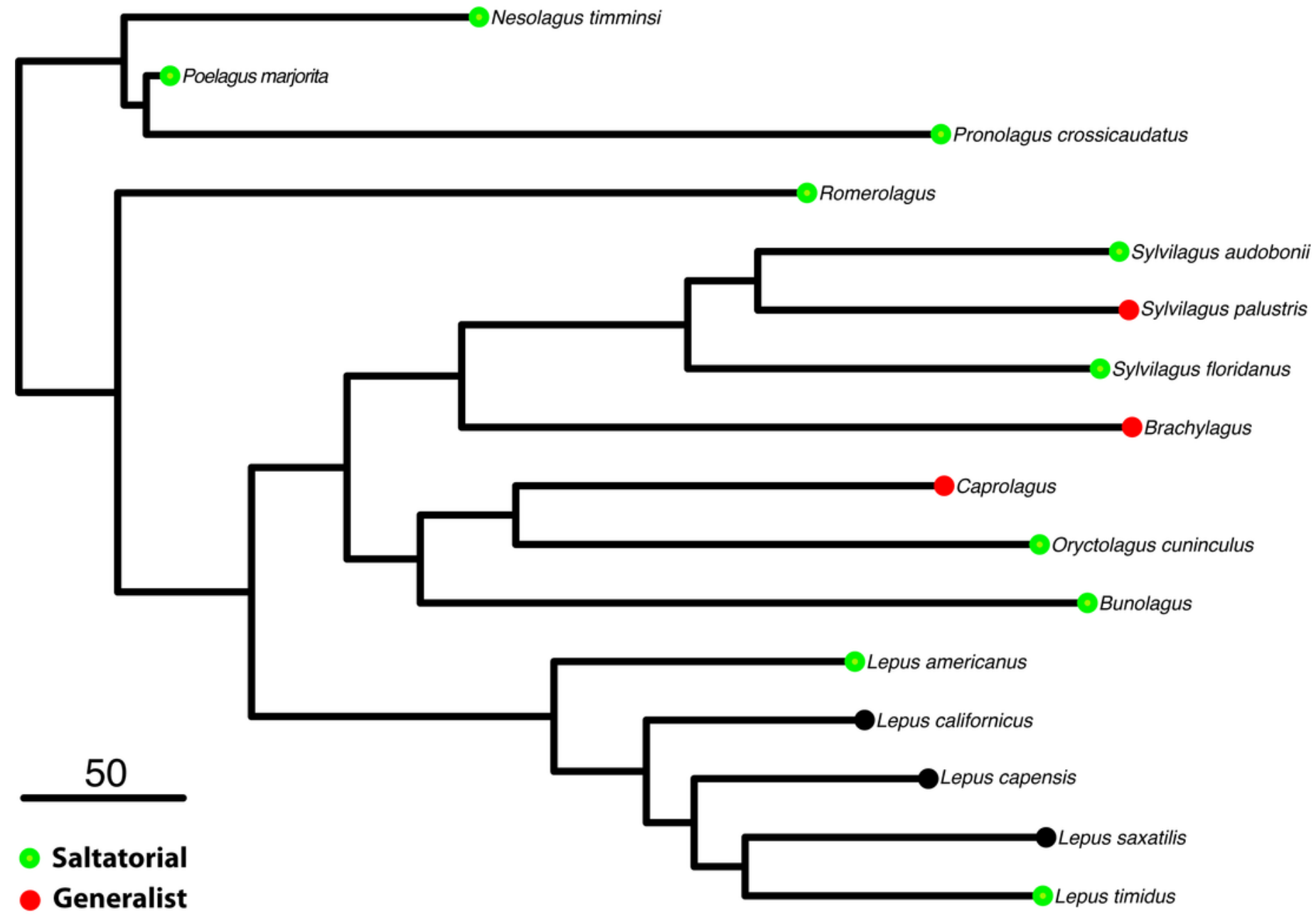


4

Skull measurements

FIGURE 4 - A representative leporid skull showing measurements used in this analysis. The cranium of Bunolagus monticularis (AMNH 146662) is shown in ( $a$ and b) right lateral (top), (c) dorsal (lower left), and (d) ventral (lower right) views. Abbreviations follow Table 1. See figure 3 for a description of Facial Tilt (FT). 

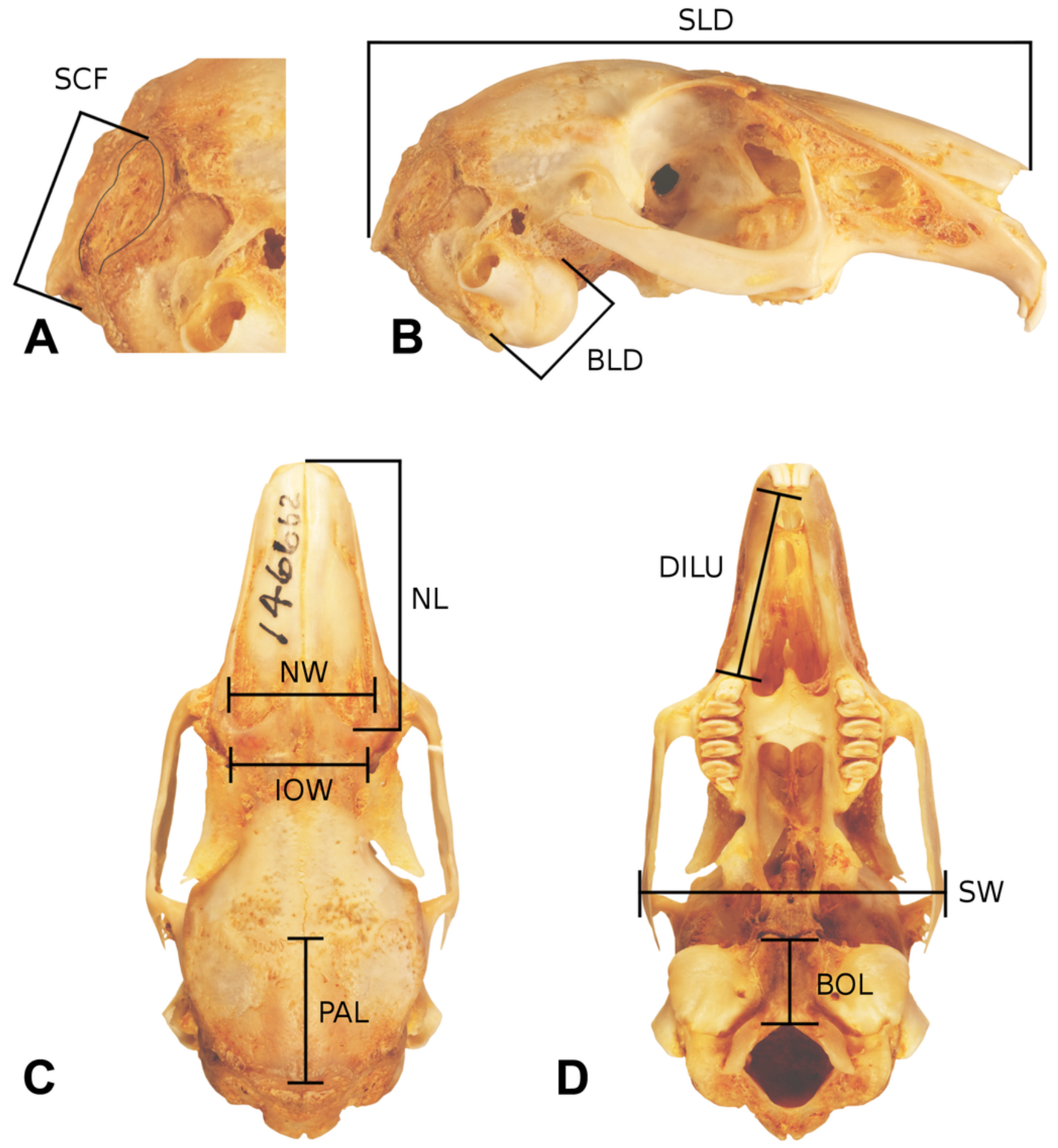


\section{5}

\section{Facial tilt ANOVA}

FIGURE 5 - Box and whisker plot summarizing facial tilt angle for all specimens, showing how the angle differs between locomotor types (a) and burrowing behavior (b).
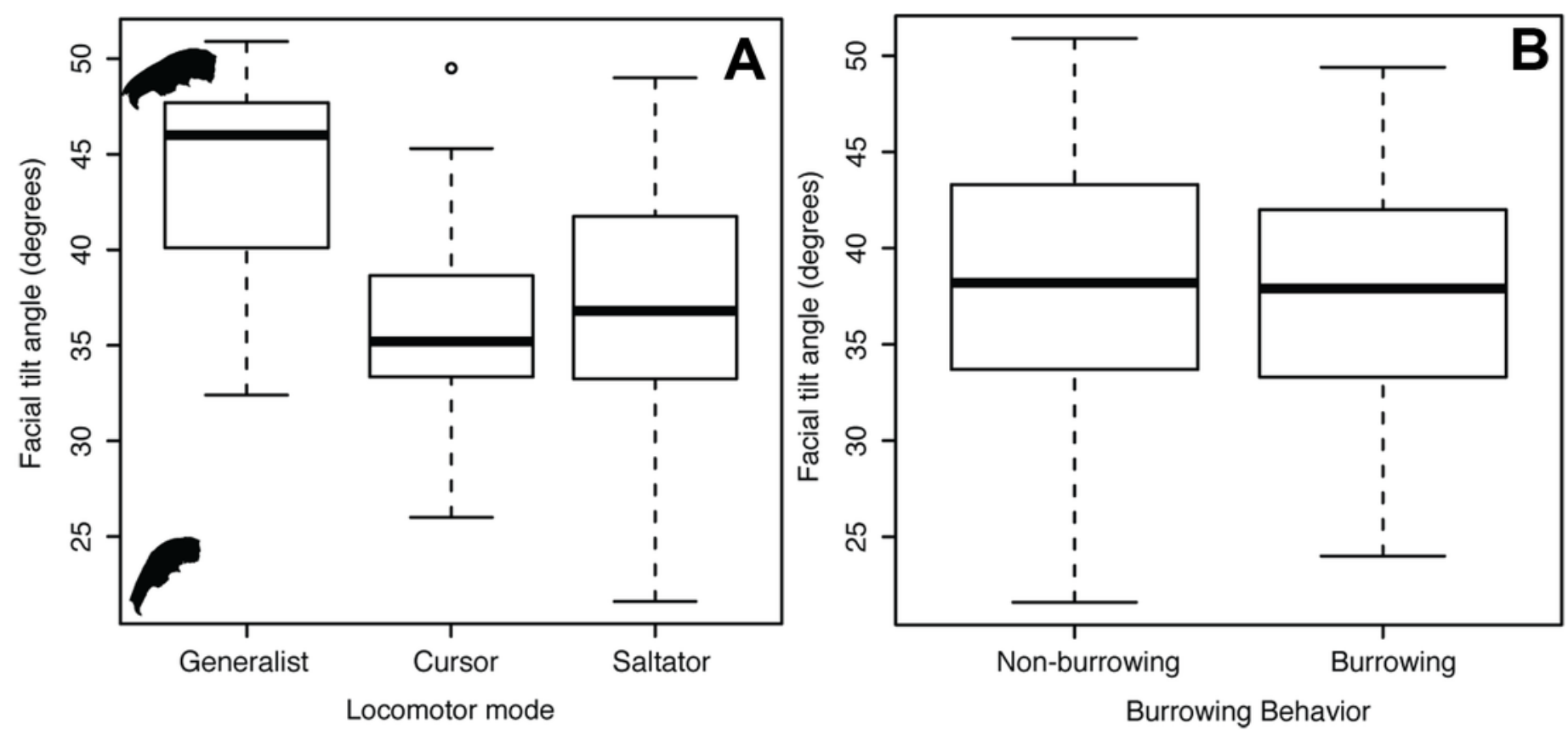


\section{6}

Multivariate PCAs

FIGURE 6 - Principal components analysis of 10 log-shape ratios measurements describing cranial shape for all specimens. Biplots show PC1 vs PC2 (top) and PC3 vs PC4 (bottom). a) Colored symbols by species. b) colored by LOC (with species symbols). Details of the loadings of each variable in the PCA are presented in Table 3.
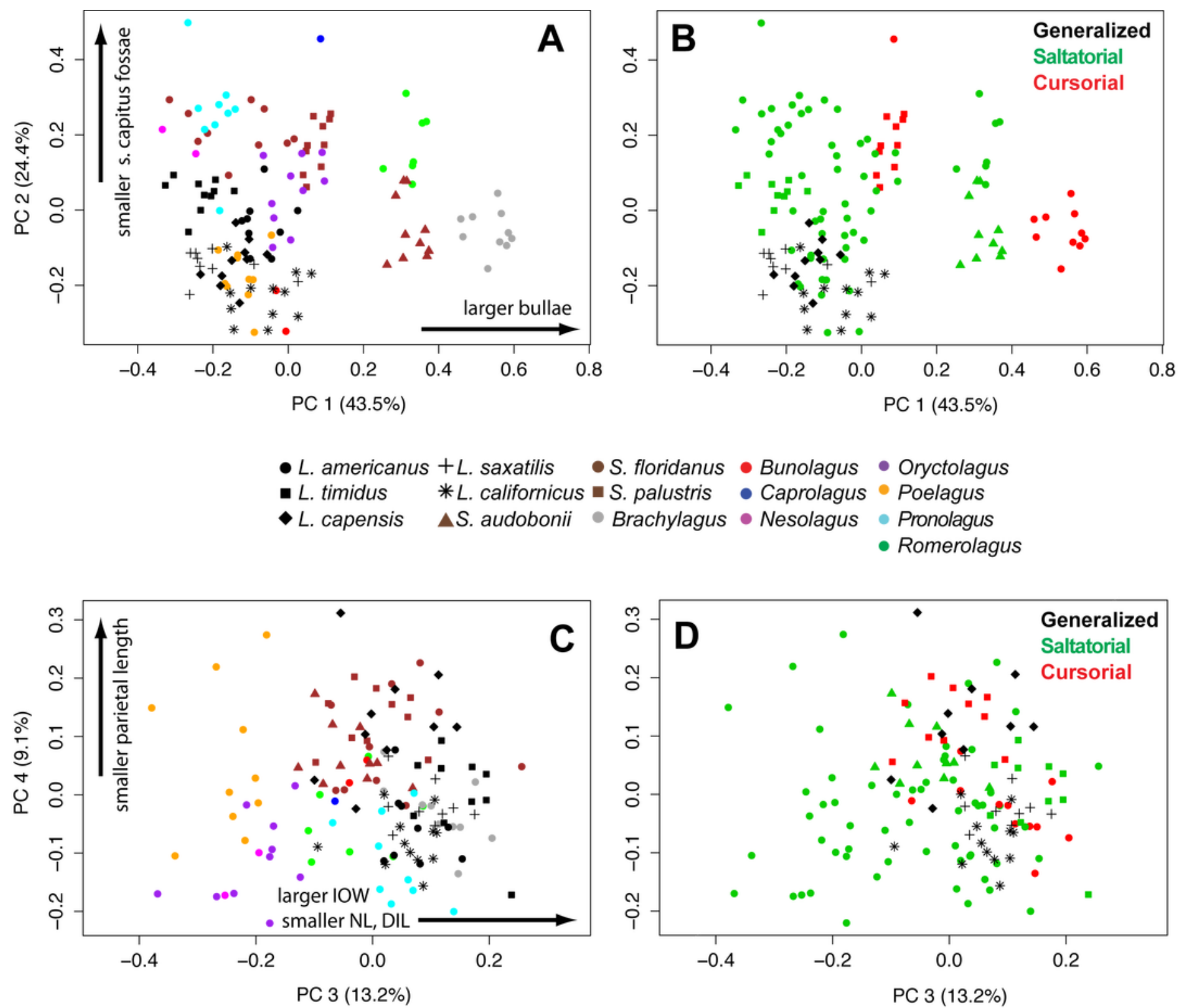


\section{Table 1 (on next page)}

Leporid species studied 
2 Table 1. Leporid species included in this study

\begin{tabular}{lllll}
\hline Species & Locomotion Type & Burrowing & Abbreviation n \\
& & & & 7 \\
\hline Romerolagus & Saltatorial & Yes & Ro & 2 \\
Bunolagus & Saltatorial & Yes & $\mathrm{Bu}$ & 2 \\
Caprolagus & Generalized & Yes & $\mathrm{Ca}$ & 10 \\
Brachylagus & Generalized & Yes & $\mathrm{Br}$ & 10 \\
Sylvilagus floridanus & Saltatorial & No & Sfl & 10 \\
Sylvilagus palustris & Generalized & No & Spal & 10 \\
Sylvilagus audobonii & Saltatorial & Yes & Sau & 10 \\
Poelagus marjorita & Saltatorial & No & Po & 10 \\
Pronolagus crossicaudatus & Saltatorial & No & Pc & 10 \\
Oryctolagus cuninculus & Saltatorial & Yes & Oc & 2 \\
Nesolagus timminsi & Saltatorial & Yes & Nt & 10 \\
Lepus americanus & Saltatorial & No & Lam & 10 \\
Lepus timidus & Saltatorial & Yes & Lti & 10 \\
Lepus capensis & Cursorial & Yes & Lcap & 12 \\
Lepus californicus & Cursorial & No & Lcal & 9 \\
Lepus saxatilis & Cursorial & No & Lsax &
\end{tabular}




\section{Table 2 (on next page)}

Skull measurements used. 
2 Table 2. Variables used in this study and description; see figures 2 and 4 for illustrations of the 3 measurement conventions.

4

5

6
Measurement Convention

\section{BLD bulla diameter}

BOL basioccipital length

DIL diastema length

IOW interorbital width

NL nasal length

NW nasal width

PAL parietal length

SCF splenius capitis fossa

SLD skull length dorsal

SW skull width maximum diameter (in any direction) of right bulla maximum midsagittal length from anterior basioccipital to foramen magnum

maximum distance between right I2 and M1

minimum transverse width between dorsal rims of orbits

maximum parasagittal length of nasal bones (i.e., orthogonal antero-posterior but not along midline)

maximum transverse width across posterior nasal bones

maximum midsagittal length of parietal bones

maximum parasagittal length from anterior margin of M. splenius capitis insertion fossa to opisthocranion maximum midsagittal length from anterior nasal bones to Opisthocranion_(just dorsal to incisors) to opisthocranion maximum transverse width across zygomatic processes 


\section{Table $\mathbf{3}$ (on next page)}

PCA loadings 
2 Table 3. The first four principal component (PC) axes contribute to $90.2 \%$ of the total variation of 3 the ten log normal variables. For each PC, the proportion of total variance (\%) and the loadings 4 on these are given. The variables with the highest loading are shown in bold and are discussed 5 within the text.

6

\begin{tabular}{lcrrr}
\hline & PC1 & \multicolumn{1}{c}{ PC2 } & \multicolumn{1}{c}{ PC3 } & \multicolumn{1}{c}{ PC4 } \\
\hline $\begin{array}{l}\text { Proportion } \\
\text { of variance }\end{array}$ & 43.5 & 24.4 & 13.2 & 9.1 \\
BLD & $\mathbf{0 . 8 5 0 4 6 8 7 3}$ & 0.02545804 & 0.016857617 & 0.272291215 \\
BOL & 0.159862063 & 0.161106564 & 0.012761305 & -0.070830236 \\
DIL & -0.246528468 & -0.026035317 & $\mathbf{- 0 . 4 1 5 1 3 6 2 3 1}$ & 0.156169866 \\
\hline IOW & -0.249260494 & 0.331660879 & $\mathbf{0 . 6 8 1 5 8 9 5 5 5}$ & 0.259415969 \\
NL & -0.175108112 & 0.062932441 & $\mathbf{- 0 . 5 0 5 9 3 9 6 5 7}$ & 0.130829626 \\
NW & -0.296951523 & 0.01926985 & 0.131337875 & 0.224903873 \\
PAL & 0.027064391 & 0.140782388 & 0.078947604 & $\mathbf{- 0 . 8 6 6 2 1 3 3 6 1}$ \\
SCF & -0.050436754 & $\mathbf{- 0 . 9 0 5 4 0 2 1 7 3}$ & 0.218089373 & -0.039704014 \\
SLD & -0.064043373 & 0.114113325 & -0.185926838 & 0.027064132 \\
SW & 0.044933539 & 0.076114004 & -0.032580602 & -0.093927069 \\
\hline
\end{tabular}

